\title{
An interhemispheric comparison of GPS phase scintillation with auroral emission observed at the South Pole and from the DMSP satellite
}

Paul Prikryl ${ }^{1, \star}$, Yongliang Zhang ${ }^{2}$, Yusuke Ebihara ${ }^{3}$, Reza Ghoddousi-Fard ${ }^{4}$, Periyadan T. Jayachandran ${ }^{5}$, Joe Kinrade ${ }^{6}$, Cathryn N. Mitchell ${ }^{6}$, Allan T. Weatherwax ${ }^{7}$, Gary Bust ${ }^{2}$, Pierre J. Cilliers ${ }^{8}$, Luca Spogli ${ }^{9}$, Lucilla Alfonsi ${ }^{9}$, Vincenzo Romano ${ }^{9}$, Baiqi Ning ${ }^{10}$, Guozhu Li ${ }^{10}$, Martin J. Jarvis ${ }^{11}$, Donald W. Danskin ${ }^{12}$, Emma Spanswick ${ }^{13}$, Eric Donovan ${ }^{13}$, Mike Terkildsen ${ }^{14}$

1 Communications Research Centre, Ottawa, ON, Canada

2 Johns Hopkins University Applied Physics Laboratory, Laurel, MD, United States

3 Research Institute for Sustainable Humanosphere, Kyoto University, Kyoto, Japan

4 Natural Resources Canada, Geodetic Survey Division, Ottawa, ON, Canada

5 University of New Brunswick, Physics Department, Fredericton, NB, Canada

${ }^{6}$ University of Bath, Electronic and Electrical Engineering, Bath, United Kingdom

7 Siena College, Physics and Astronomy, Loudonville, NY, United States

8 South African National Space Agency, Space Science Directorate, Hermanus, South Africa

9 Istituto Nazionale di Geofisica e Vulcanologia, Sezione Roma 2, Rome, Italy

${ }^{10}$ Institute of Geology and Geophysics, Chinese Academy of Sciences, Beijing, China

${ }^{11}$ British Antarctic Survey, Physical Sciences Division, Cambridge, United Kingdom

${ }^{12}$ Natural Resources Canada, Geomagnetic Laboratory, Ottawa, ON, Canada

${ }^{13}$ University of Calgary, Department of Physics and Astronomy, AB, Canada

${ }^{14}$ IPS Radio and Space Services, Bureau of Meteorology, Haymarket, NSW, Australia

\section{Article history}

Received November 11, 2012; accepted March 27, 2013.

Subject classification:

Scintillations, Solar-terrestrial interaction, Space weather, Solar variability and solar wind, Magnetic storms.

\section{ABSTRACT}

The global positioning system (GPS) phase scintillation caused by highlatitude ionospheric irregularities during an intense high-speed stream (HSS) of the solar wind from April 29 to May 5, 2011, was observed using arrays of GPS ionospheric scintillation and total electron content monitors in the Arctic and Antarctica. The one-minute phase-scintillation index derived from the data sampled at $50 \mathrm{~Hz}$ was complemented by a proxy index (delta phase rate) obtained from 1-Hz GPS data. The scintillation occurrence coincided with the aurora borealis and aurora australis observed by an all-sky imager at the South Pole, and by special sensor ultraviolet scanning imagers on board satellites of the Defense Meteorological Satellites Program. The South Pole (SP) station is approximately conjugate with two Canadian High Arctic Ionospheric Network stations on Baffin Island, Canada, which provided the opportunity to study magnetic conjugacy of scintillation with support of riometers and magnetometers. The GPS ionospheric pierce points were mapped at their actual or conjugate locations, along with the auroral emission over the South Pole, assuming an altitude of $120 \mathrm{~km}$. As the aurora brightened and / or drifted across the field of view of the all-sky imager, sequences of scintillation events were observed that indicated conjugate auroras as a locator of simultaneous or delayed bipolar scintillation events. In spite of the greater scintillation intensity in the auroral oval, where phase scintillation sometimes exceeded 1 radian during the auroral break-up and substorms, the percentage occurrence of moderate scintillation was highest in the cusp. Interhemispheric comparisons of bipolar scintillation maps show that the scintillation occurrence is significantly higher in the southern cusp and polar cap.

\section{Introduction}

Rapid fluctuations of the amplitude and phase of transionospheric radio signals degrade positioning accuracy and cause cycle slips, which can lead to complete 
loss of signal lock and operational outages that can affect the performance of radio communication and navigation systems. Scintillation of high-latitude global positioning system (GPS), or in general, Global Navigational Satellite System (GNSS), is caused by ionospheric irregularities that are produced by energetic particle precipitation and by patches of enhanced plasma density convecting in the polar cap. These high-latitude phenomena occur in both hemispheres, sometimes simultaneously, and they are threaded by magnetic field lines that are either closed or open; i.e., connected to the interplanetary magnetic field (IMF). Conjugate auroras during auroral break-up and substorms show similarities as well as asymmetries [Sato et al. 1998, Sato et al. 2005, Laundal and Østgaard 2009]. Auroral arc brightening and substorm intensification are known to correlate with GPS phase scintillation and cycle slips, which appear to be caused by ionospheric irregularities that are produced by auroral precipitation [Smith et al. 2008, Prikryl et al. 2010]. Scintillation-causing irregularities are also produced in the cusp/ cleft region by shear-driven plasma density instability, and in the polar cap by gradient-drift instability, particularly at the trailing edge of the polar cap patches [Basu et al. 1998, Carlson 2012].

GPS scintillation climatology studies in both hemispheres have shown that as a function of magnetic local time and geomagnetic latitude, phase scintillation primarily occurs on the dayside in the ionospheric cusp, and in the night-side auroral oval [Spogli et al. 2009, Li et al. 2010, Alfonsi et al. 2011, Prikryl et al. 2011a]. Li et al. [2010] conducted a statistical study of GPS phasescintillation occurrence at approximately conjugate locations at Ny-Alesund, Svalbard, and Zhongshan, Antarctica, which are typically located in the daytime cusp and in the auroral oval, or poleward of at night. An interhemispheric comparison of high-latitude ionospheric scintillation during a geomagnetic storm caused by a magnetic cloud that was embedded in a high-speed solar wind found similarities, but also asymmetries, between the northern and southern auroral zones, cusps, and polar caps [Prikryl et al. 2011b, Kinrade et al. 2012]. Energetic particle precipitation during substorms is routinely recorded by riometers to study substorm injections [Spanswick et al. 2007], and the associated sudden increases in GPS total electron content (TEC) can be used to track substorm expansion [Watson et al. 2011].

In this study, we focus on the GPS phase scintillation that is associated with aurora and riometer absorption at the poleward edge of the night-side and dayside auroral oval observed during a week-long highspeed solar-wind event. In particular, phase scintillation associated with auroral emission and riometer absorption at the South Pole, Antarctica, and at two sites in the Arctic, are compared. The SP $\left(74.1^{\circ} \mathrm{S}\right.$ corrected geomagnetic $[\mathrm{CGM}]$ latitude) is approximately conjugate with Qikiqtarjuaq (QIK; $75.4^{\circ} \mathrm{N}$ ) and Iqaluit (IQA; $\left.72.4^{\circ} \mathrm{N}\right)$. Another approximately conjugate pair was provided by Zhongshan station in Antarctica and the stations on the Svalbard archipelago. Mapping of the ionospheric pierce points (IPPs) on the auroral images
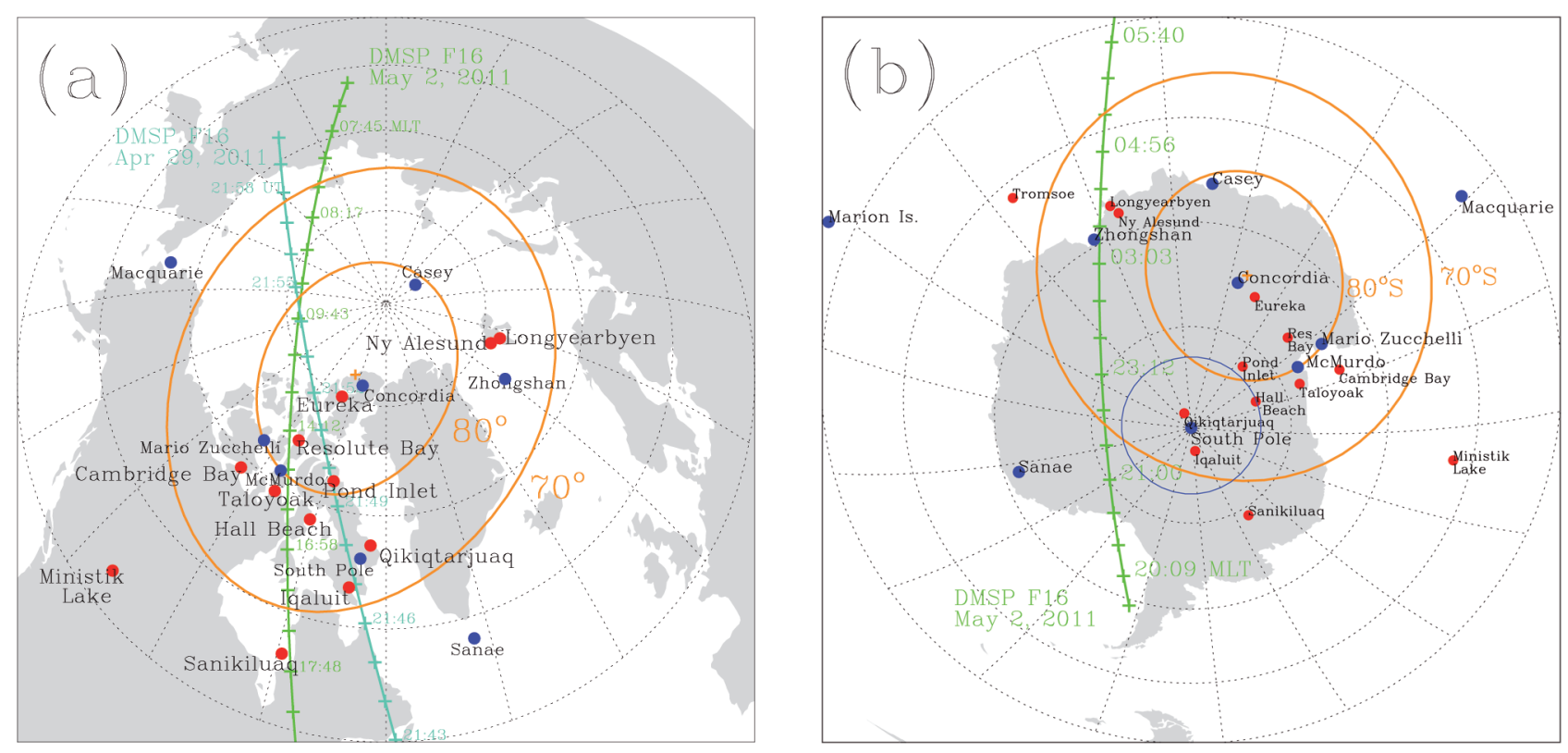

Figure 1. (a) The CHAIN and European GISTMs (red dots) and conjugate locations of southern hemisphere GISTMs (blue dots). Corrected geomagnetic (CGM) latitudes $70^{\circ} \mathrm{N}$ and $80^{\circ} \mathrm{N}$ and two DMSP F16 satellite tracks are superposed. The times shown on the DMSP tracks are in UT and MLT for April 29 (cyan) and May 2 (green), respectively. (b) The southern hemisphere GISTMs (blue dots) and conjugate locations of CHAIN and European GISTMs (red dots). The field of view of an all-sky imager at SP is shown. Corrected geomagnetic (CGM) latitudes $70^{\circ} \mathrm{S}$ and $80^{\circ} \mathrm{S}$ (orange) and a DMSP F16 satellite track are superposed. 
indicated simultaneity of bipolar scintillation events in some cases. However, delays between the bipolar scintillation events that were also observed can be explained by drifting conjugate auroral forms sequentially crossing the IPPs in the northern and southern hemispheres. Finally, to compare the phase scintillation index with its proxy index, scintillation occurrence maps for the northern and southern high latitudes are presented.

\section{Instruments and data}

The Canadian High Arctic Ionospheric Network (CHAIN) [Jayachandran et al. 2009] consists of ten specialized GPS ionospheric scintillation and TEC monitors (GISTMs) and six Canadian Advanced Digital ionosondes (CADIs) distributed in the auroral oval, the cusp, and the polar cap (http:/ / chain.physics.unb.ca/ chain). The SP GPS receiver operations were a collaborative effort of the University of Bath (Bath, UK) and Siena College (Loudonville, USA). The GISTM of the South African National Antarctic Expedition in Antarctica is operated by the South African Space Science Directorate. The GSV 4004B receivers can track up to 11 satellites simultaneously at L1 (1575.42 MHz) and L2 (1227.60 MHz) frequencies. They can record the signal phase and amplitude at a sampling rate of $50 \mathrm{~Hz}$, and compute the amplitude scintillation index, $S_{4}$, which is the standard deviation of the amplitude normalized to its mean value, and the phase scintillation index, $\sigma_{\Phi}$, which is the standard deviation of the detrended phase. CHAIN is supported by radars, riometers, optical instruments and magnetometers of the Canadian Geospace Monitoring Program [Liu 2005, Mann et al. 2008], including the Northern Solar Terrestrial Array [Donovan et al. 2003]. An all sky imager is operated in a collaboration between Kyoto University (Kyoto, Japan) and Siena College at the SP Station [Ebihara et al. 2010]. This consists of a fish eye lens, an automated filter changer, and a back illuminated, air cooled CCD camera with resolution set at $512 \times 512$ pixels for an electron aurora. The station is also equipped with an imaging riometer and magnetometers. Figure 1 shows the locations of the GISTMs in the northern and southern high latitudes, along with the conjugate locations of the respective opposite hemisphere stations. For the geographic and geomagnetic latitudes of the stations and the station acronyms, see Prikryl et al. [2011b; their Table 1].

To overcome the limited geographic cover of the GISTMs, other GNSS data sampled at $1 \mathrm{~Hz}$ were used to obtain the phase scintillation proxy index. A proxy index 'delta phase rate' (DPR), in units of $\mathrm{m} / \mathrm{s}$, was obtained as a difference between the ionospheric delays encountered by GPS phase measurements over two consecutive epochs $1 \mathrm{~s}$ apart, averaged over $30 \mathrm{~s}$ [Ghoddousi-Fard and Lahaye 2012].

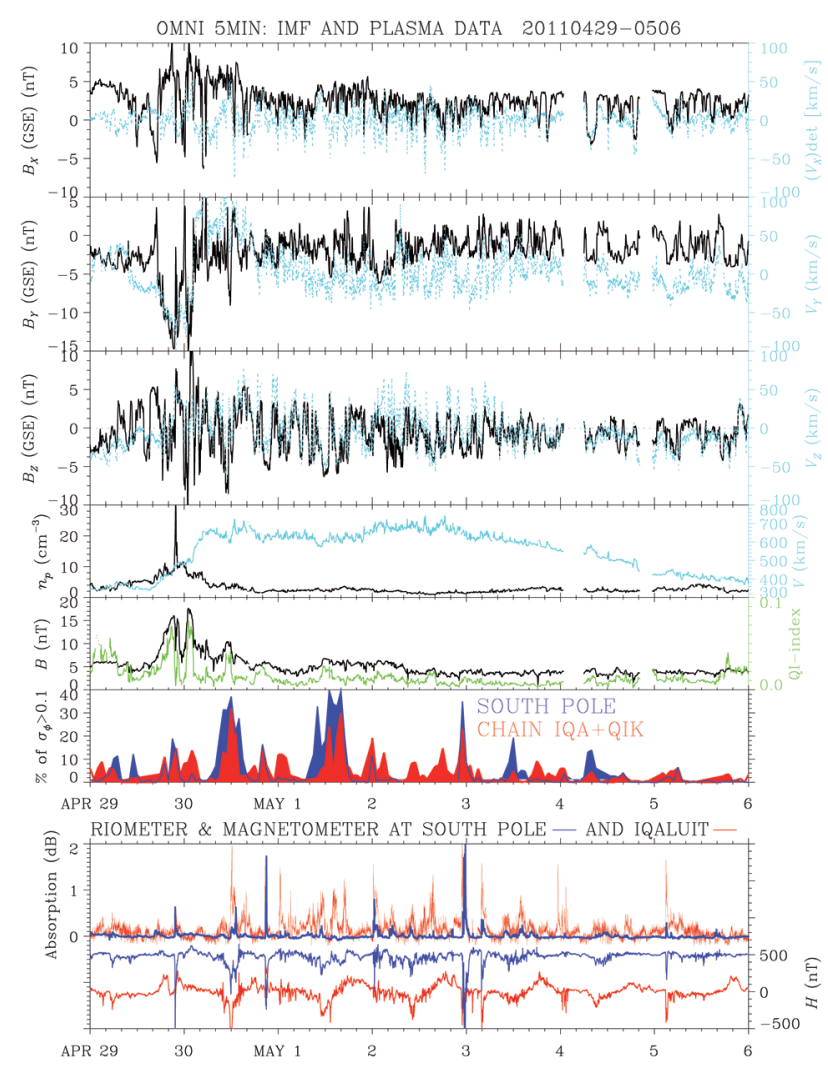

Figure 2. Solar-wind magnetic field and plasma parameters from the OMNIWeb dataset combining available solar-wind-monitor data projected to the nose of the Earth bow shock. The quasi invariant (QI) index is superposed as the green line. Hourly occurrences of phase scintillation, riometer absorption and magnetic H-component observed at Iqaluit-Qikiqtarjuaq (IQA/QIK) and South Pole (SP) are shown in red and dark blue, respectively.

A special sensor ultraviolet scanning imager (SSUSI) was on board the DMSP satellites (F16 to F18). This measures auroral and airglow emissions in FUV bands, and provides partial global auroral images in five 'colors': $121.6 \mathrm{~nm}$ (proton aurora), $130.4 \mathrm{~nm}$ (O emission), 135.6 $\mathrm{nm}$ (O emission), $140 \mathrm{~nm}$ to $150 \mathrm{~nm}$ (Lyman-BirgeHopfield [LBH]S: N2 LBH short band) and $165 \mathrm{~nm}$ to $180 \mathrm{~nm}$ (LBHL: N2 LBH long band) [Paxton et al. 2002]. The LBHS and LBHL bands were used to derive the energy flux and mean energy of precipitating electrons in the auroral oval [Zhang and Paxton 2008, and references therein]. SSUSI takes 15 auroral images in both hemispheres every day, and the images have spatial resolution down to $10 \mathrm{~km}$ at nadir. The presented SSUSI auroral images have been re-binned with a grid side of $25 \mathrm{~km} \times 25$ $\mathrm{km}$. The SSUSI is almost the same as a global ultraviolet imager [see Zhang and Paxton 2008].

\section{Auroral activity and scintillation during the solar- wind high-speed stream}

\subsection{Solar-wind parameters}

A plasma HSS from a coronal hole with a solar-wind speed $V$ that reached up to $c a .700 \mathrm{~km} / \mathrm{s}$ swept past the 
Earth between April 29 and May 6, 2011. Figure 2 shows the 5-min averages of the magnetic field and solar-wind velocity components in Geocentric Solar Ecliptic System coordinates (Figure 2, top three panels), the total flow velocity $V$, the proton density $n_{p}$, and the total magnetic field magnitude $B$, from the OMNI dataset, projected to subsolar bow shock (http:/ / om niweb.gsfc.nasa.gov/). The quasi-invariant index, QI (Figure 2, green), is equivalent to the ratio of the solarwind magnetic to ram pressures, or the inverse of the magnetic Mach number squared [Osherovich et al. 1999]. It is thus defined as QI $\equiv\left(B^{2} / 2 \mu_{0}\right) /\left(\rho V^{2} / 2\right)=M_{A}^{-2}$, where $\mu_{0}$ is the permeability of free space, $\rho$ is the plasma density, $V$ is the plasma velocity, and $M_{A}$ is the magnetic Mach number $\left(M_{A}=V / V_{A}\right.$, where $V_{A}$ is the Alfvén speed). As a single nondimensional quantity of fundamental importance, QI characterizes the solarwind geoeffectiveness and correlates with solar activity indices. The compression ridge of the HSS was associated with enhanced QI values and a sharp increase in the solar-wind density that was followed by a peak in the dynamic pressure of $16 \mathrm{nPa}$, and with the IMF northward turning at ca. 21:55 UT, ending a period of ca. $4 \mathrm{~h}$ of IMF $B_{Z}<0$. The co-rotating interaction region (CIR) HSS interface arrived at ca. 22:00 UT on April 29, 2011. This was followed by large-amplitude Alfvén waves. The corresponding components of the IMF and ion velocity fluctuations were correlated, while the total IMF magnitude and density $n_{p}$ remained relatively constant (Figure 2). For sunward-oriented background IMF $\left(B_{X}>0\right)$, the positive correlations indicated anti-sunward propagating Alfvén waves [Belcher and Davis 1971] advected in the solar wind. Figure 2 also shows the hourly occurrences of phase scintillation observed by the GPS scintillation monitors at IQA-QIK and SP (Figure 2, red, blue, respectively). Significant phase scintillation commenced with the ar-

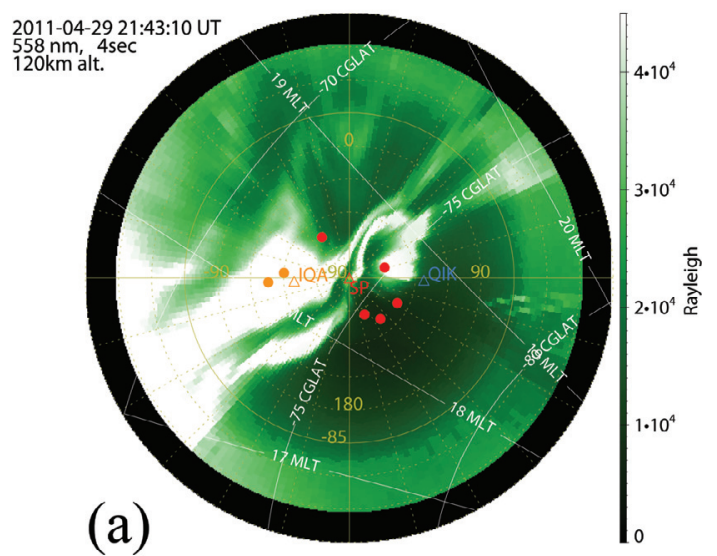

PHASE SCINTILLATION IQALUIT 29-APR-2011 PRN 1-32

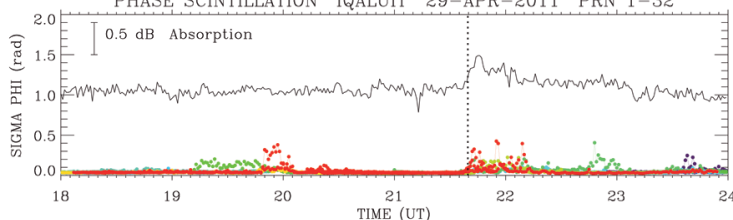

PHASE SCINTILLATION QIKIQTARJUAQ 29-APR-2011 PRN 1-32

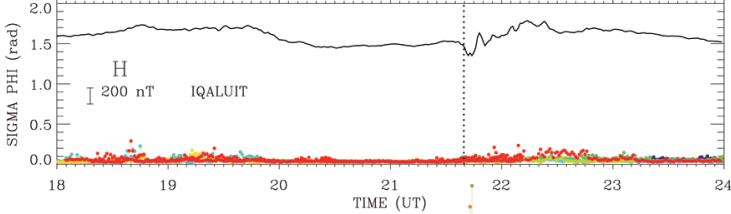

PHASE SCINTILLATION SOUTH POLE 29-APR-2011 PRN 1-32

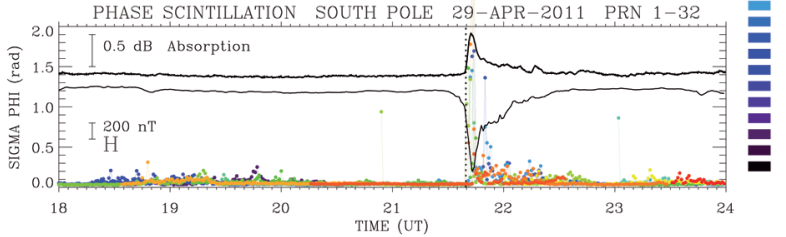

OMNI 1-MIN IMF (GSE) 20110429

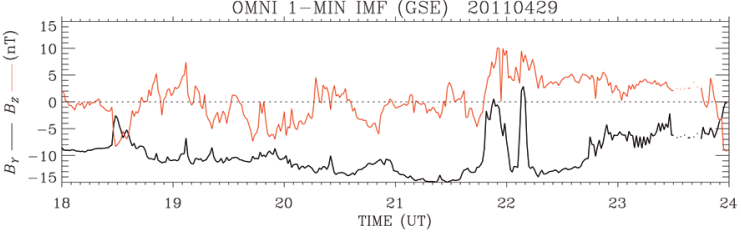

Figure 3. In colors (top three panels), the phase scintillation index $\sigma_{\Phi}$ observed at elevations above $30^{\circ}$ on April 29, 2011. The riometer absorption and the $H$ components of the ground magnetic field measured at IQA and SP are superposed in the scintillation panels. The IMF $B_{Y}$ and $B_{Z}$ are shown in the bottom panel.

rival of the HSS and continued for several days. The scintillation occurrence was associated with enhanced riometer absorption and ground-magnetometer perturbations of the horizontal component $\mathrm{H}$ at SP and IQA (Figure 2, bottom panel).

\subsection{April 29, 2011}

The arrival of the HSS sparked substorm activity and a geomagnetic storm ( $K p$ and Dst indices reaching $5+$ and $-44 \mathrm{nT}$, respectively). Bright auroras that were associated with scintillation were observed at SP on

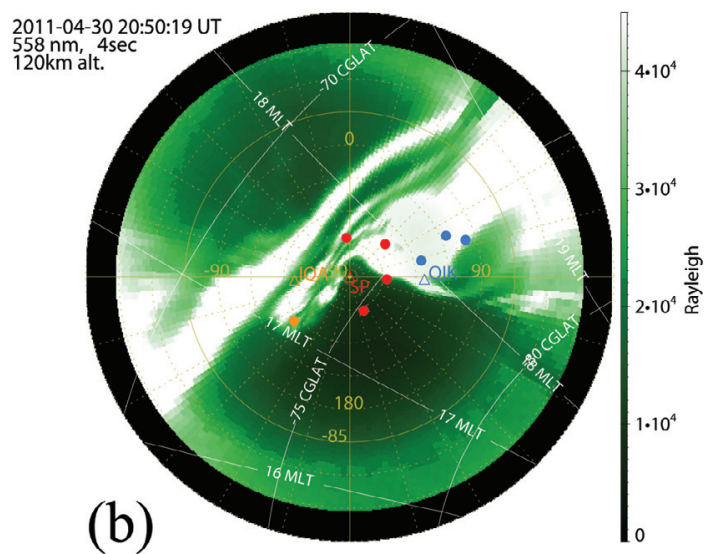

Figure 4. The 557.7-nm all-sky images during substorms on (a) April 29 and (b) April 30, 2011, mapped on a geographic grid assuming an altitude of $120 \mathrm{~km}$. The IPPs for which $\sigma_{\Phi}>0.15 \mathrm{rad}$ are shown at SP (red) and at locations conjugate to the northern hemisphere stations of IQA (orange) and QIK (blue). The corrected geomagnetic (CGM) latitudes and MLT (white) are superposed over the geographic grid (yellow). 


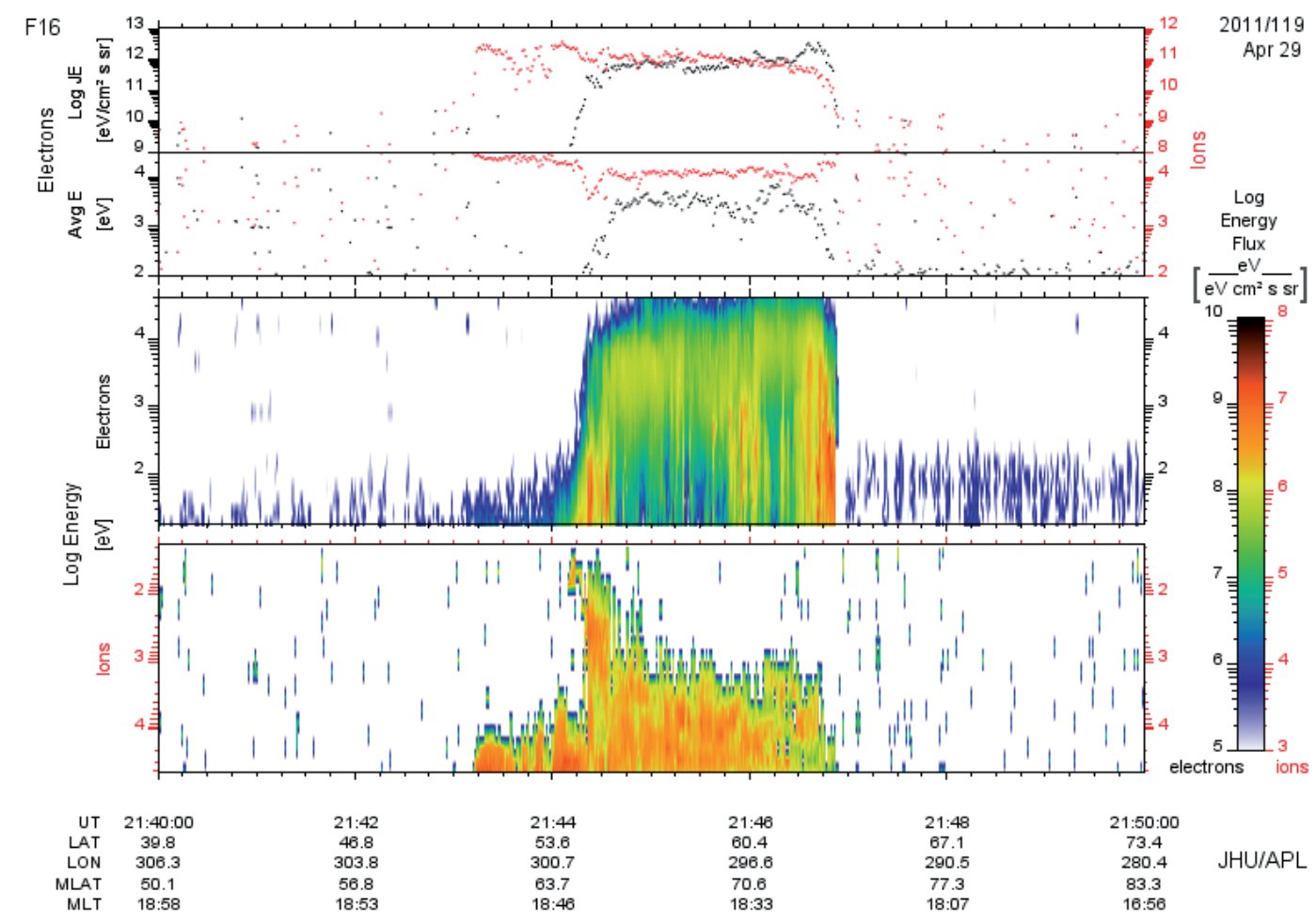

Figure 5. Precipitating particle fluxes observed by the F16 DMSP satellite during a pass over the northern auroral oval.

successive nights. On April 29, after a substorm onset at ca. 21:30 UT, an auroral arc brightened near the horizon and the aurora quickly expanded to the zenith. The Wp index [Nosé et al. 2012], which characterizes the Pi2 wave power at low latitude that closely precedes substorm onset, peaked at 21:29 UT (http: / / s-cubed.info). This is consistent with the magnetic signature of the substorm observed by ground-based magnetometers in Scandinavia in the midnight sector (not shown). Figure 3 shows the phase scintillation index $\sigma_{\Phi}$ as observed at IQA, QIK and SP, which were located in the early evening sector (between 18:00 and 19:00 magnetic local time [MLT]) at the time of the substorm onset. The nearly simultaneous onset of the riometer absorption and perturbation of the H-component at SP and IQA is indicated by vertical dotted lines. The H-component from the IQA magnetometer is shown in the middle panel of Figure 3 (there was no magnetometer at QIK). To be compared with the broad-beam riometer absorption recorded at IQA, the SP imaging riometer absorption was averaged over all 49 beams. The phase scintillation onset at 21:40 UT occurred at SP, IQA and QIK nearly simultaneously. However, the scintillation at IQA and QIK was much weaker, and the onset of riometer absorption at IQA was less abrupt, compared to SP. The GPS satellites were identified by the receiver by means of their pseudo random noise (PRN) codes and satellite numbers, as 1-32, and they were coded by color. The phase scintillation onset at 21:40 UT closely coincided with the ground mag- netic horizontal field $\mathrm{H}$-component perturbations and riometer absorption observed at IQA and SP. At SP, $\sigma_{\Phi}$ exceeded $2 \mathrm{rad}$ for two PRNs at 21:43 UT (Figure 3). At IQA and QIK, $\sigma_{\Phi}$ reached only $0.4 \mathrm{rad}$ and $0.2 \mathrm{rad}$, respectively. The IMF (Figure 3; bottom panel) indicated a large dawnward $\left(B_{Y}<0\right)$ component at the time of the scintillation onset, but recovered to zero $10 \mathrm{~min}$ later, while $B_{Z}$ changed to northward.

Figure 4a shows an all-sky image mapped in geographic coordinates, with the SP (red), IQA (orange), and QIK (blue) IPPs at an assumed altitude of $120 \mathrm{~km}$, for various PRNs when $\sigma_{\Phi}>0.15 \mathrm{rad}$. The conjugate locations of IQA and QIK, and the associated IPPs are shown. The weak scintillation that was observed at QIK did not exceed the 0.15-rad threshold, and indeed, the QIK conjugate location mapped away from the bright aurora over SP at this time. However, several IPPs that indicated enhanced $\sigma_{\Phi}$ are shown for SP and IQA. The conjugate locations of PRNs for IQA are collocated with the brightest (saturated) parts of the auroral forms, which suggests some degree of aurora conjugacy and the presence of auroral emission directly above IQA in the northern hemisphere. The IPPs for SP are associated with the rayed arcs (corona) display in the zenith. During this time, the horizontal component of the magnetic field experienced a maximum negative deflection of ca. $1000 \mathrm{nT}$, while the cosmic radio noise absorption due to energetic particle precipitation peaked 2 min earlier. A moderate magnetic-field disturbance accompanied by riometer ab- 
sorption in IQA was coincident with the event at SP.

The onset of phase scintillation occurred at the poleward border of the auroral oval that was observed by the DMSP-F16 satellite in the northern hemisphere, over Labrador and Baffin Island. The satellite crossed the poleward border of the auroral oval at 21:47 UT, when it passed very close to IQA (Figure 5). The DMSP particle detectors observed electron precipitation fluxes with energies that exceeded $4 \mathrm{keV}$, which indicated the presence of auroral arcs [Newell et al. 2009]. It can be noted that prior to the substorm event, there was weaker scintillation that was observed for $3 \mathrm{~h}$ to $4 \mathrm{~h}$ that started at 18:00 UT, simultaneously at SP, IQA and QIK, after the southward turning of the IMF $B_{Z}$ associated with the arrival of the HSS / CIR (Figure 2), which was followed by enhanced values of the indices of geomagnetic activity, including AE and Wp (http://s-cubed.info). At this time, low intensity multiple rayed arcs were observed by the imager at SP.

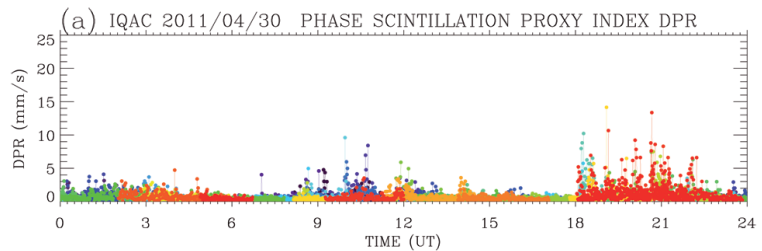

(b) PHASE SCINTILLATION IQALUIT 30-APR-2011 PRN 1-32

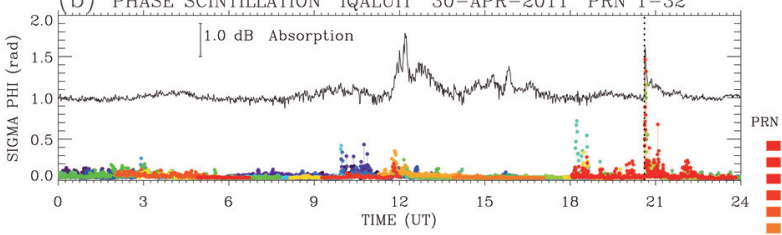

PHASE SCINTILLATION QIKIQTARJUAQ 30-APR-2011 PRN 1-32

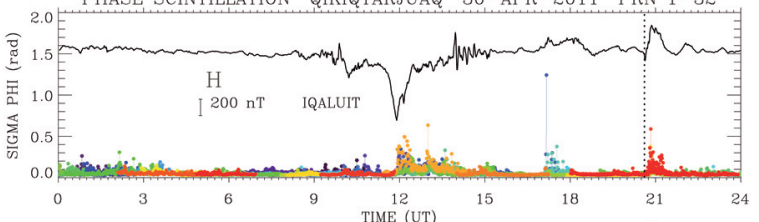

PHASE SCINTILLATION SOUTH POLE 30-APR-2011 PRN 1-32

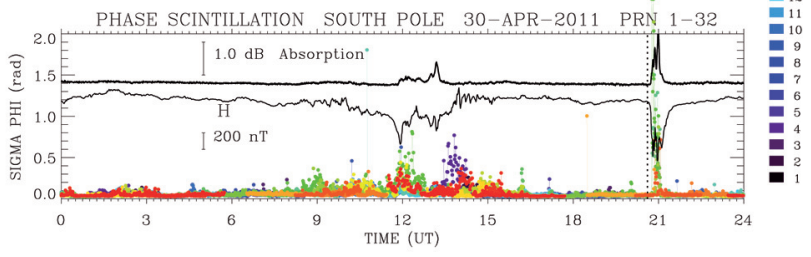

OMNI 1-MIN IMF (GSE) 20110430

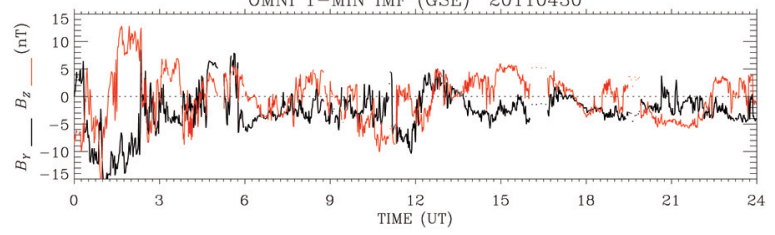

Figure 6. (a) The scintillation proxy DPR index for IQA on April 30, 2011. (b) The phase scintillation index $\sigma_{\Phi}$ observed at elevations above $30^{\circ}$. The riometer absorption and the $H$ components of the ground magnetic field measured at IQA and SP are superposed in the scintillation panels. The IMF $B_{Y}$ and $B_{Z}$ are shown in the bottom panel.

\subsection{April 30, 2011}

On April 30, 2011, after a period of several hours (09:00 to 15:00 UT) of concurrent scintillation at both hemispheres in the morning sector, another auroral substorm resulted in the onset of phase scintillation at SP, IQA and QIK in the early evening sector (Figure 6). The DPR proxy index that is shown in Figure 6a is further discussed in Section 5. For the present discussion here, we refer to the four panels in Figure $6 \mathrm{~b}$. Similar to the previous day, the substorm onset occurred in the pre-midnight Scandinavian sector, and the substorm Wp-index increased at 20:33 UT. The onset was followed by a spike in phase scintillation at IQA (20:38 UT), and with a delay of ca. $7 \mathrm{~min}$, by approximately simultaneous scintillation onsets at SP and QIK (20:45 UT). The riometer absorption, the ground magnetic field perturbation and scintillation onset at IQA at 20:38 UT is indicated by the vertical dotted lines in the top three panels of Figure 6 . The aurora brightness exceeded $44 \mathrm{kR}$ (Figure $4 \mathrm{~b}$ ) when $\sigma_{\Phi}$ peaked at $1.5 \mathrm{rad}$ at SP. Most of the IPPs, including those shown at their conjugate locations (IQA, QIK), were collocated with the bright aurora. However, the peak riometer absorption and scintillation at IQA (when the bright aurora would be expected over IQA) preceded the onset of scintillation at QIK by $13 \mathrm{~min}$. The scintillation at QIK occurred concurrently with the scintillation at SP, but was weaker. The IMF at this time was southward, with $B_{Y}$ fluctuating around zero.

It can be noted that not only were the bright auroras during substorms associated with significant scintillation. Rayed arcs and coronas in the morning and post-noon sectors were also co-located with moderateto-weak scintillation in the morning sector on April 30. This is illustrated in Figure 7a, which shows a corona display at its peak at 12:08 UT, when the H-component perturbations were maximized, and the riometer absorption also peaked and/or was enhanced at IQA and SP.

\subsection{May 1, 2011}

In the next two days, continuing large-scale solarwind Alfvén waves resulted in many periods of southward IMF that caused ionospheric disturbances and scintillation. A series of pseudo break-ups in the midnight sector associated with moderate scintillation events occurred in both hemispheres on May 1 between 00:00 and 06:00 UT. Figure 7b shows the rayed arcs that reached maximum intensity at 00:32 UT, which resulted in scintillation at SP and IQA. The mapped IPPs of enhanced scintillations were closely collocated with arcs, while there was no scintillation observed from QIK at this time, when the QIK conjugate location was far removed from the arc observed near zenith at SP. Instead, 

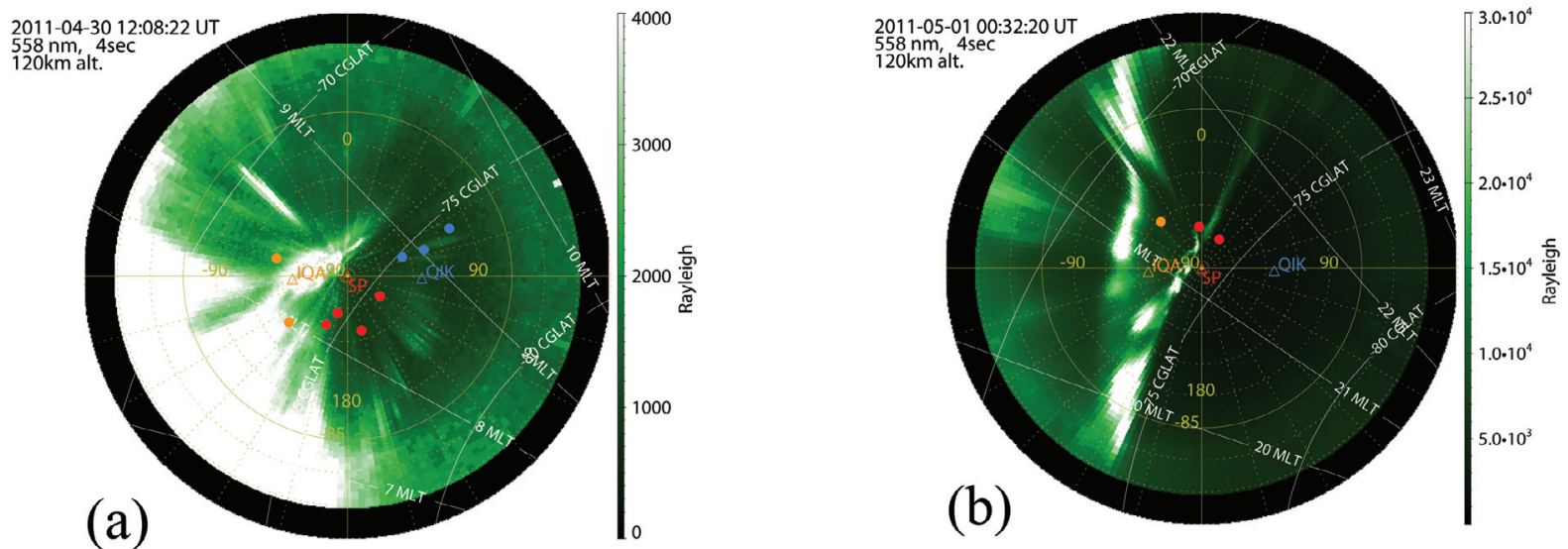

Figure 7. The 557.7-nm images of (a) a corona display in the morning sector on April 30, and (b) pre-midnight pseudo-break-up of an arc on May 1, 2011.
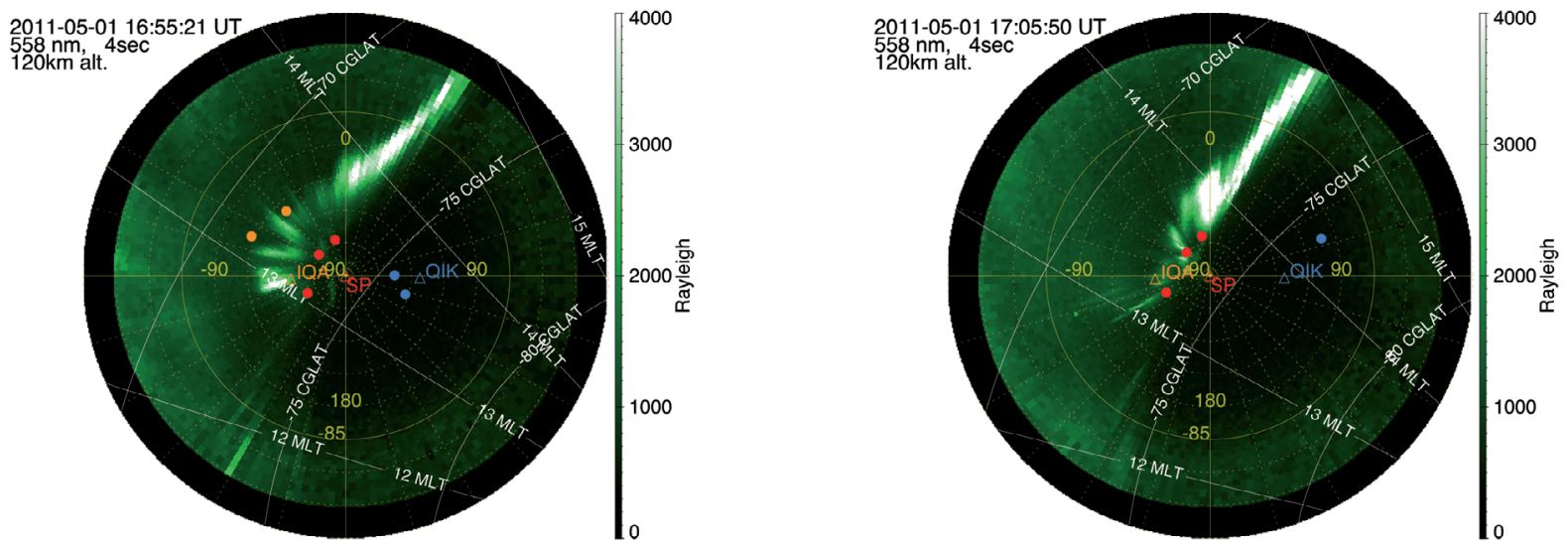

Figure 8. Mapped 557.7-nm images showing a poleward moving auroral form on May 1, 2011.

moderate scintillation was observed at SP between 08:00 and 18:00 UT with $\sigma_{\Phi}$ frequently reaching or exceeding $0.5 \mathrm{rad}$, particularly near the cusp where poleward-moving auroral forms were observed. Figure 8 shows a poleward-moving auroral form that fanned towards the zenith as it moved polewards. Equatorward of the zenith, it intercepts IQA IPPs that detected scintillation first. When reaching the zenith, the scintillation at IQA ended, while it continued at SP and QIK. In addition to aurora, copious patches were observed in the polar cap by McMurdo radar (not shown) that continued through the next day, as a result of coupling of large amplitude Alfvén waves to the dayside magnetopause [Prikryl et al. 1999]. Scintillation due to polar cap patches is not the focus of this study, and so it is only briefly discussed below.

\subsection{May 2-5, 2011}

On May 2, the riometers and magnetometers at IQA and SP (Figure 9) showed delayed onsets of auroral activity at ca. 00:11 and 00:15 UT, respectively, which started a period of drifting arcs observed over SP. An arc that brightened near the north-western horizon was detached from the poleward edge of the auroral oval near $-70^{\circ} \mathrm{CGM}$ latitude, and moved polewards (Figure 10). As the arc moved polewards, strong scintillation was first detected at IQA, then at SP, and finally at QIK (Figures 9, 10). After it moved past zenith at SP, the arc split into two. The equatorward portion brightened and then dimmed. As the poleward arc drifted back to zenith, moderate scintillation was observed, this time in a reversed sequence: QIK followed by SP and IQA. At ca. 00:32 UT, the arc brightened and broke up, which resulted in scintillation observed at all three stations. This sequence of scintillation and absorption events suggested that similar auroral forms occurred and evolved at conjugate locations. The IMF $B_{Z}$ was at nearly zero while $B_{Y}$ reached zero between 00:10 and 00:15 UT, but was slightly negative (dawnward) at other times.

More asynchronous interhemispheric scintillation events were observed during a substorm that occurred before 23:00 UT (Figure 9). The substorm index Wp and AE index both peaked at ca. 22:47 UT (http://scubed.info). The riometer absorption and scintillation activity commenced at IQA at 22:43 UT, but scintillation was delayed until after 23:00 UT at QIK. At SP, the 

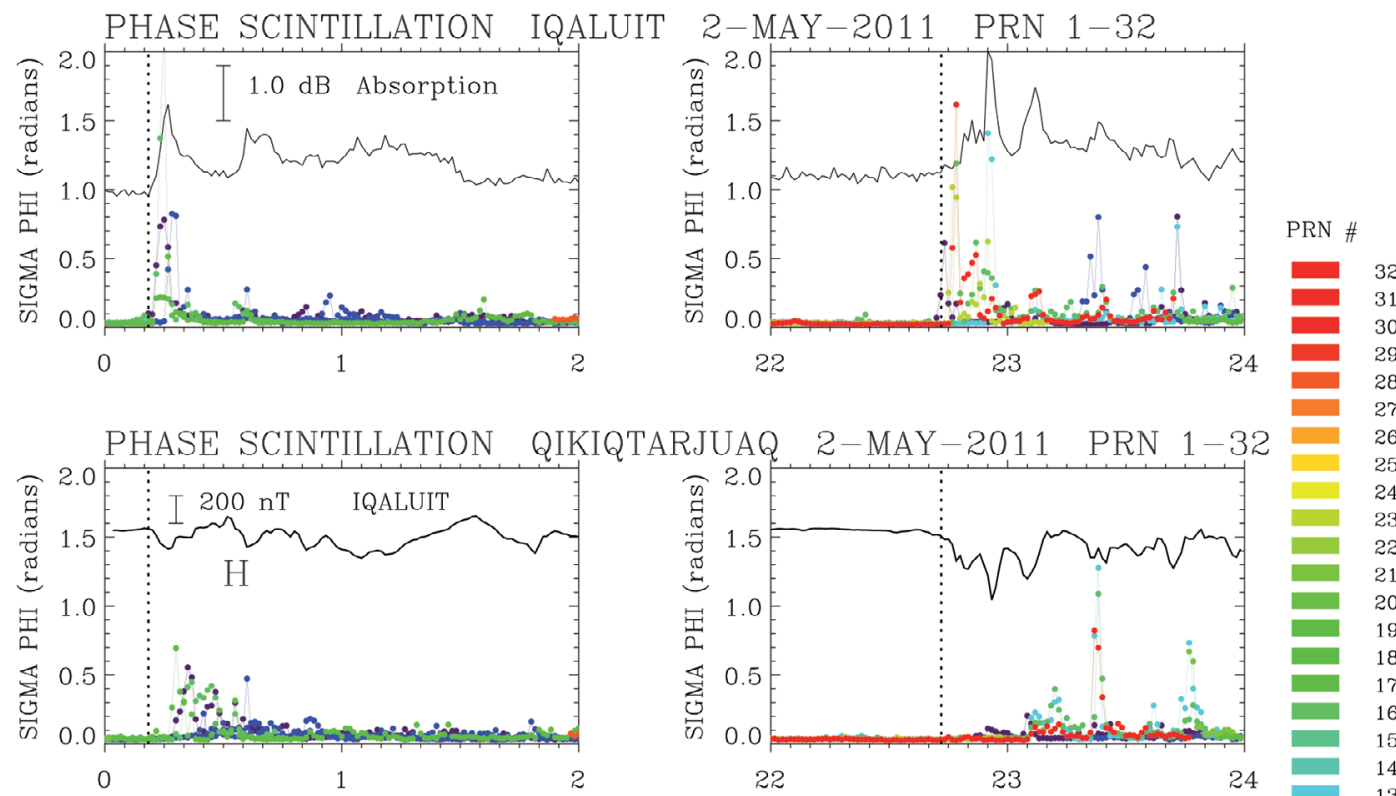

PHASE SCINTILLATION SOUTH POLE 2-MAY-2011 PRN 1-32
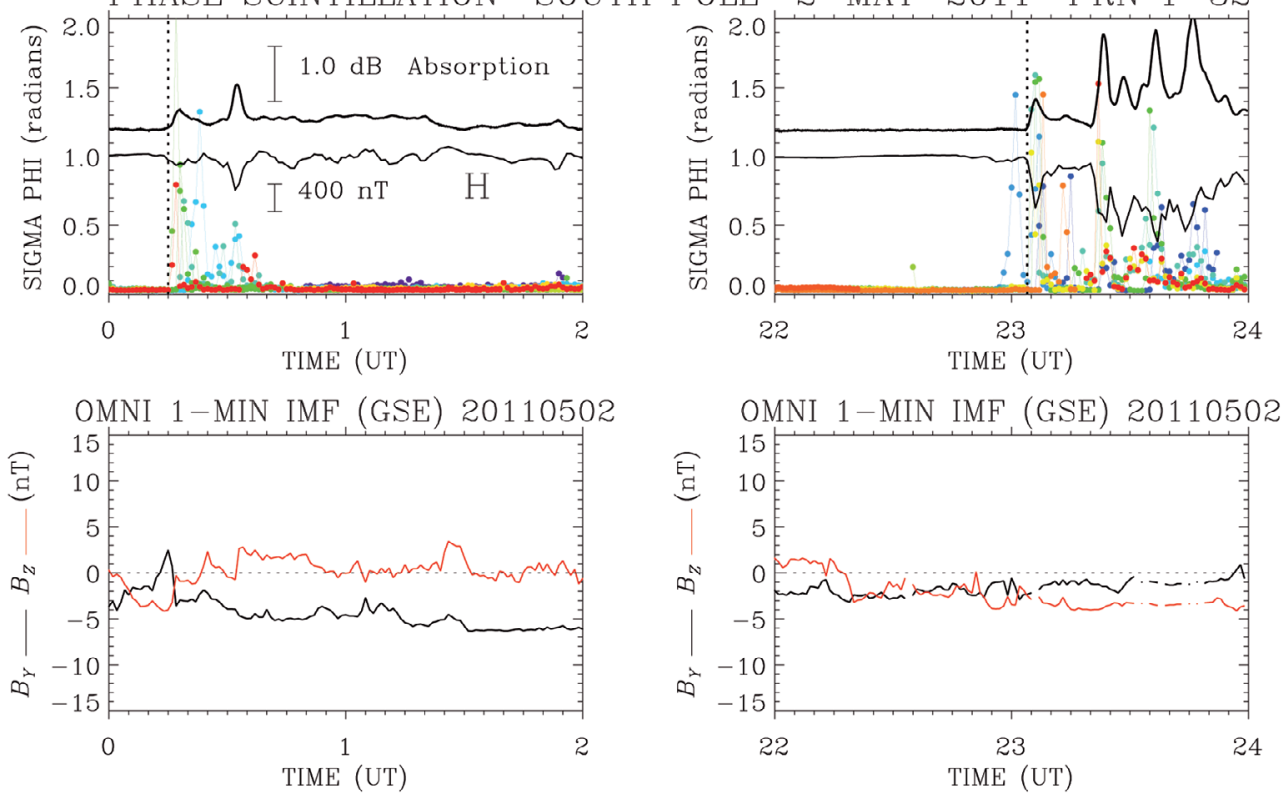

Figure 9. The phase scintillation index $\sigma_{\Phi}$ observed at elevations above $30^{\circ}$ on May 2, 2011. The riometer absorption and the $\mathrm{H}$ components of the ground magnetic field measured at IQA and SP are superposed in the scintillation panels. The IMF $B_{Y}$ and $B_{Z}$ are shown in the bottom panels.

substorm onset occurred at ca. 23:04 UT, although this was preceded by weak absorption and one PRN showed a scintillation peak a few minutes earlier. Similar to the event discussed above (Figure 10), an auroral arc brightened near the north-western horizon at SP at ca. 22:45 UT, and expanded polewards, reaching the conjugate location of IQA by 23:00 UT (not shown). A break-up that occurred at 23:04 UT resulted in strong scintillation at SP $\left(\sigma_{\Phi}>1 \mathrm{rad}\right)$ while only a moderate scintillation was observed at QIK and IQA at that time (Figures 9, 11). A few more auroral brightenings and/or break-ups followed (see Figure 9, riometer absorption spikes at SP and IQA), each of which resulted in scintillation at all three locations (Figure 11). The IMF $B_{Z}$ and
$B_{Y}$ were both weakly negative during this event.

Figure 12a, b shows two successive SSUSI auroral image scans from DMSP F16 in the northern and southern hemispheres, respectively. The equatorward auroral boundary from a global ultraviolet imager auroral model at a fixed electron flux $\left(0.2 \mathrm{ergs} / \mathrm{s} / \mathrm{cm}^{2}\right)$ is shown in the red dashed line in Figure 12a, b. This model boundary was selected to match the SSUSI night-side boundary at the same flux threshold. In the northern hemisphere, the image captured an auroral arc brightening (observed also at SP; Figure 11) at the poleward edge of the auroral oval, with an arc being detached. The CHAIN IPPs where phase scintillation exceeded $0.1 \mathrm{rad}$ clustered prominently around IQA and QIK, as 

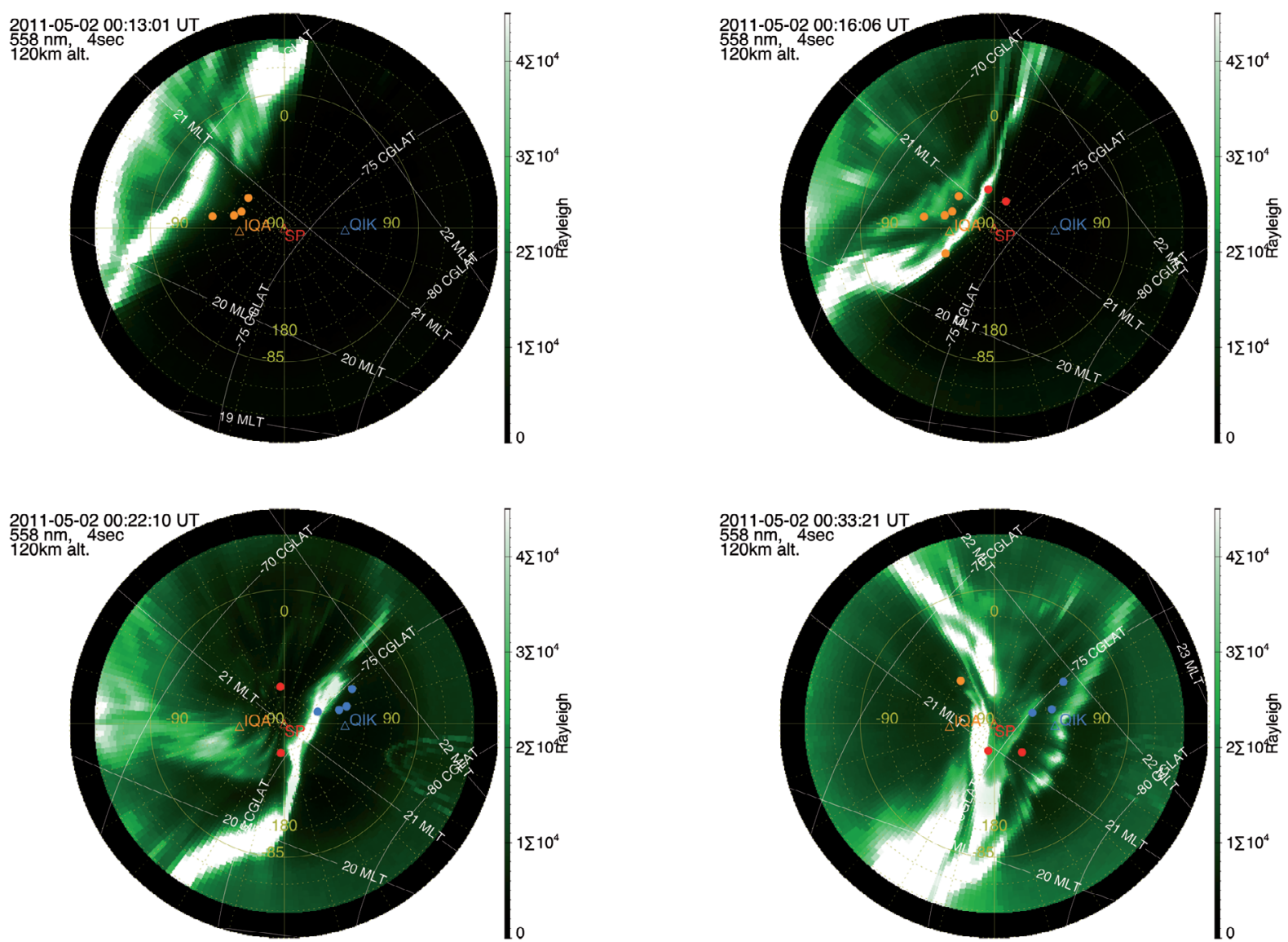

Figure 10. A sequence of mapped 557.7-nm images of a drifting arc in the pre-midnight sector on May 2, 2011.
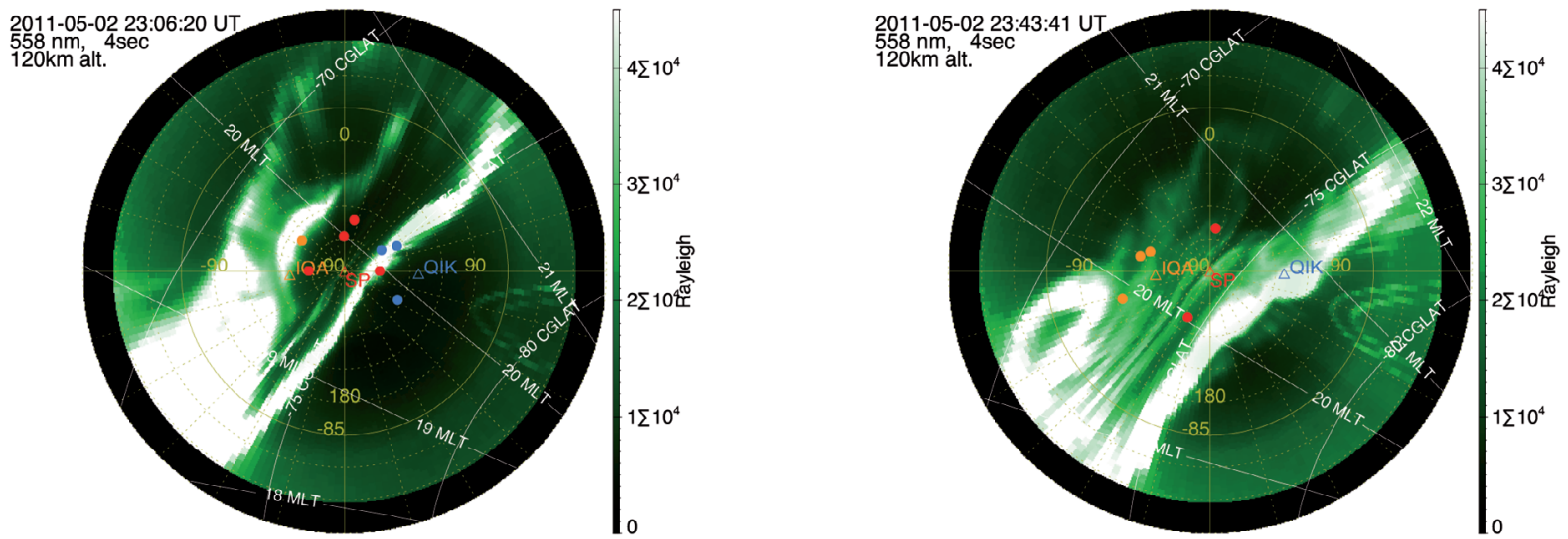

Figure 11. Mapped 557.7-nm images of an arc brightening during a substorm on May 2, 2011.

shown in blue and cyan, respectively, in Figure 12c. About 50 min later, in the southern hemisphere, the arc that is seen in Figure 11 was already detached, and stretched from the pre- to post-midnight sector. Figure $12 \mathrm{~d}$ shows the IPPs clustered around SP (green) just outside of the SSUSI image at latitudes and MLTs where the arc was joining the auroral oval, as observed at SP (Figure 11). In addition to the scintillation cluster around SP in the dusk sector at ca. 19:30 MLT, another cluster of IPPs is shown co-located with the bright part of the arc in the post-midnight sector at ca. 01:30 MLT
(Figure 12d). This cluster shows IPPs for ZHON (orange) as well as IPPs for conjugate locations of the Svalbard stations at NYA0, LYB0 and YRGN (shades of blue). These two prominent clusters of IPPs, both of which included conjugate locations, suggest that scintillation was co-located with similar large-scale conjugate arcs occurring in the respective hemispheres.

In the following days, before the activity caused by the HSS subsided, there were other coincident scintillation events at SP, IQA and QIK that were associated with riometer absorption (not shown). These included bright- 
May 2, 2011 Orbit: 38892 (DMSP F16)
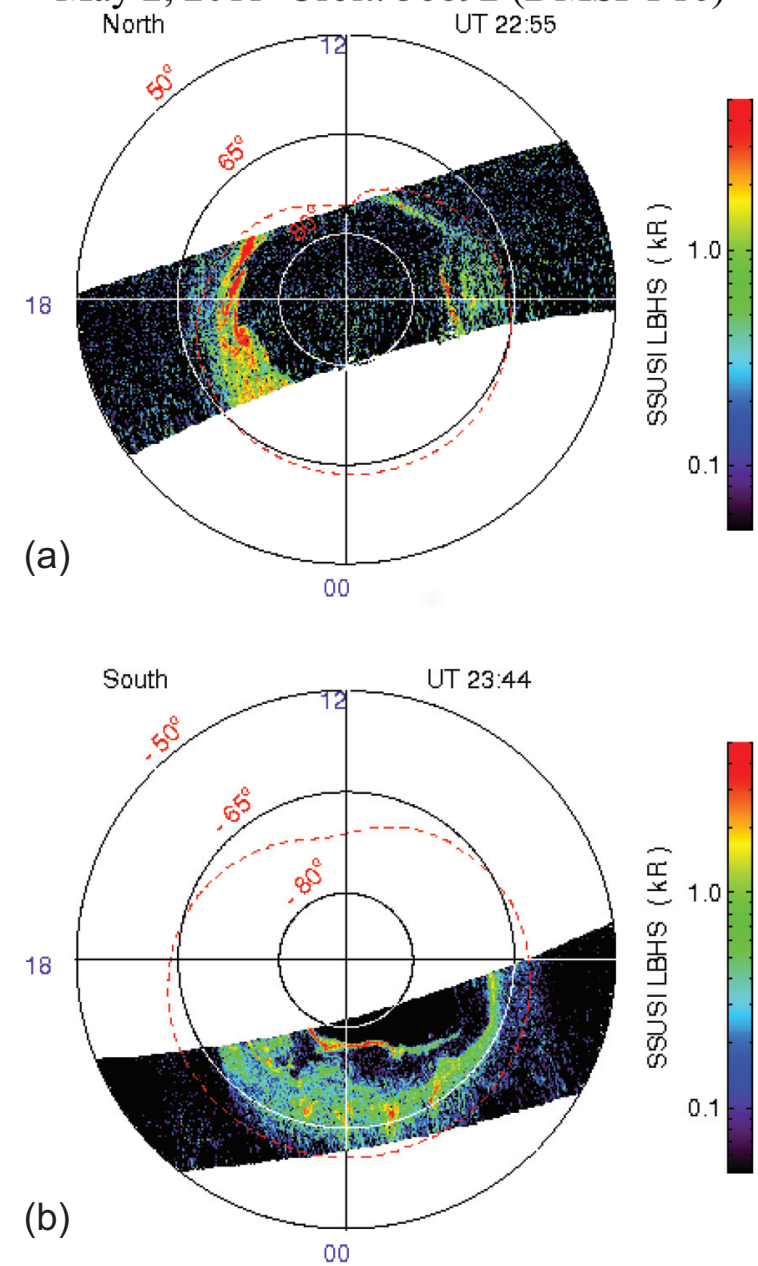

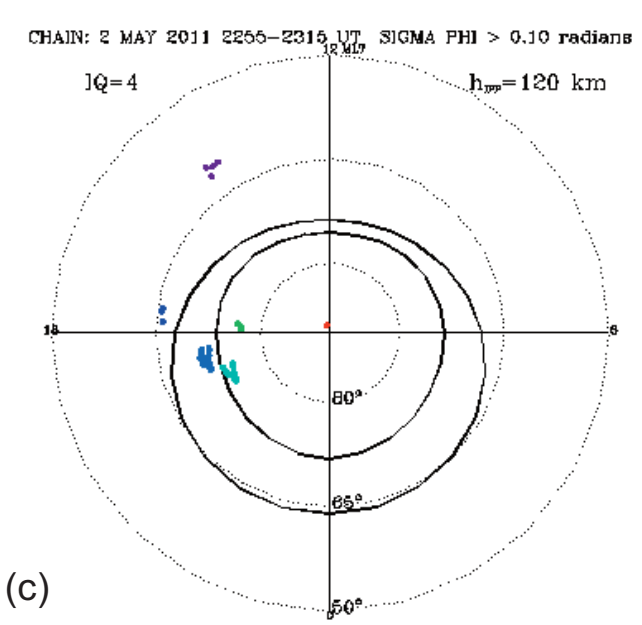

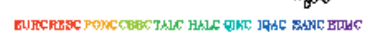

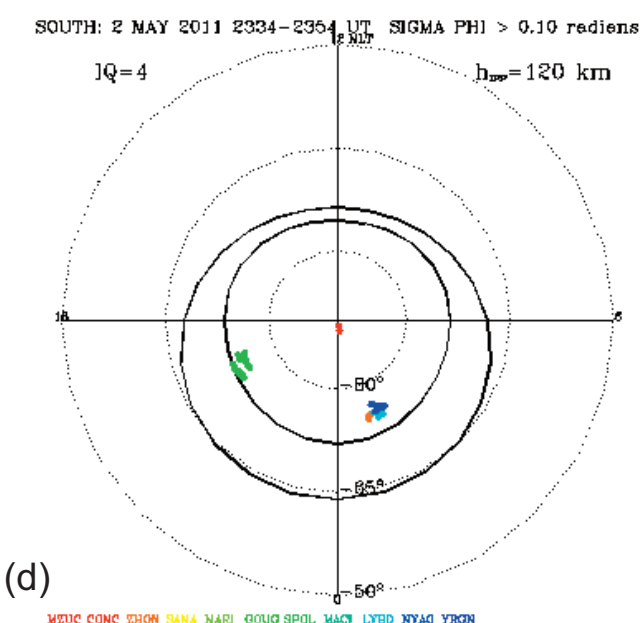

Figure 12. (a, b) Two successive SSUSI (DMSP F16) auroral image scans mapped as a function of magnetic latitude and MLT. (b, d) Corresponding maps of IPPs where scintillation exceeded $0.1 \mathrm{rad}$. The statistical auroral oval for moderately disturbed conditions is superposed.

enings of rayed auroral arcs near zenith at SP in the premidnight hours at 03:52 UT on May 3 and 02:55 UT on May 5. During a series of pre-midnight pseudo breakups on May 4 (very similar to those shown in Figures 9, 10), the aurora at SP periodically expanded polewards, but only once reached the zenith at 01:00 UT, when scintillation occurred at SP. At IQA, each brightening and poleward expansion of the auroral oval resulted in riometer absorption and a burst of scintillation, while no scintillation was observed further polewards at QIK.

\section{Auroral conjugacy of phase scintillation}

Particle precipitation during substorms, pseudo break-ups, auroral-arc brightenings, corona displays of rayed arcs, and dayside poleward moving auroral forms resulted in riometer absorption that was observed simultaneously, or with a delay of a few minutes, at approximately conjugate sites at SP and IQA. The events were associated with phase scintillation observed by GISTMs in the Arctic and Antarctic. Assuming an altitude of $120 \mathrm{~km}$, the same hemisphere and conjugate IPPs of phase scintillation events observed at southern and northern high latitudes during a period of solarwind HSS were mapped on the auroral images that were obtained by an all-sky camera at SP and SSUSI imagers on the DMSP satellites. Bipolar scintillation events, as either simultaneous or delayed, were observed by conjugate pairs of receivers where the IPPs were co-located with auroral forms that were observed by an allsky imager at SP or DMPS SUSSI. The sequences of bipolar scintillation events associated with a variety of auroral forms are consistent with the occurrence of conjugate auroras.

Simultaneity of bipolar scintillation events was observed when IPPs mapped on, or near, the auroral forms, while delays between the scintillation events can be explained by drifting conjugate auroral forms crossing the IPPs sequentially. In one instance, a large-scale conjugate auroral arc was observed from the ground by an all-sky imager at SP (Figure 11) and by the DMSP F16 satellite SSUSI imager during polar overflights (Figure 12). The southern auroral arc was observed by an all-sky imager from the ground at SP as it was detached from the poleward edge of the auroral oval (Figure 11). 

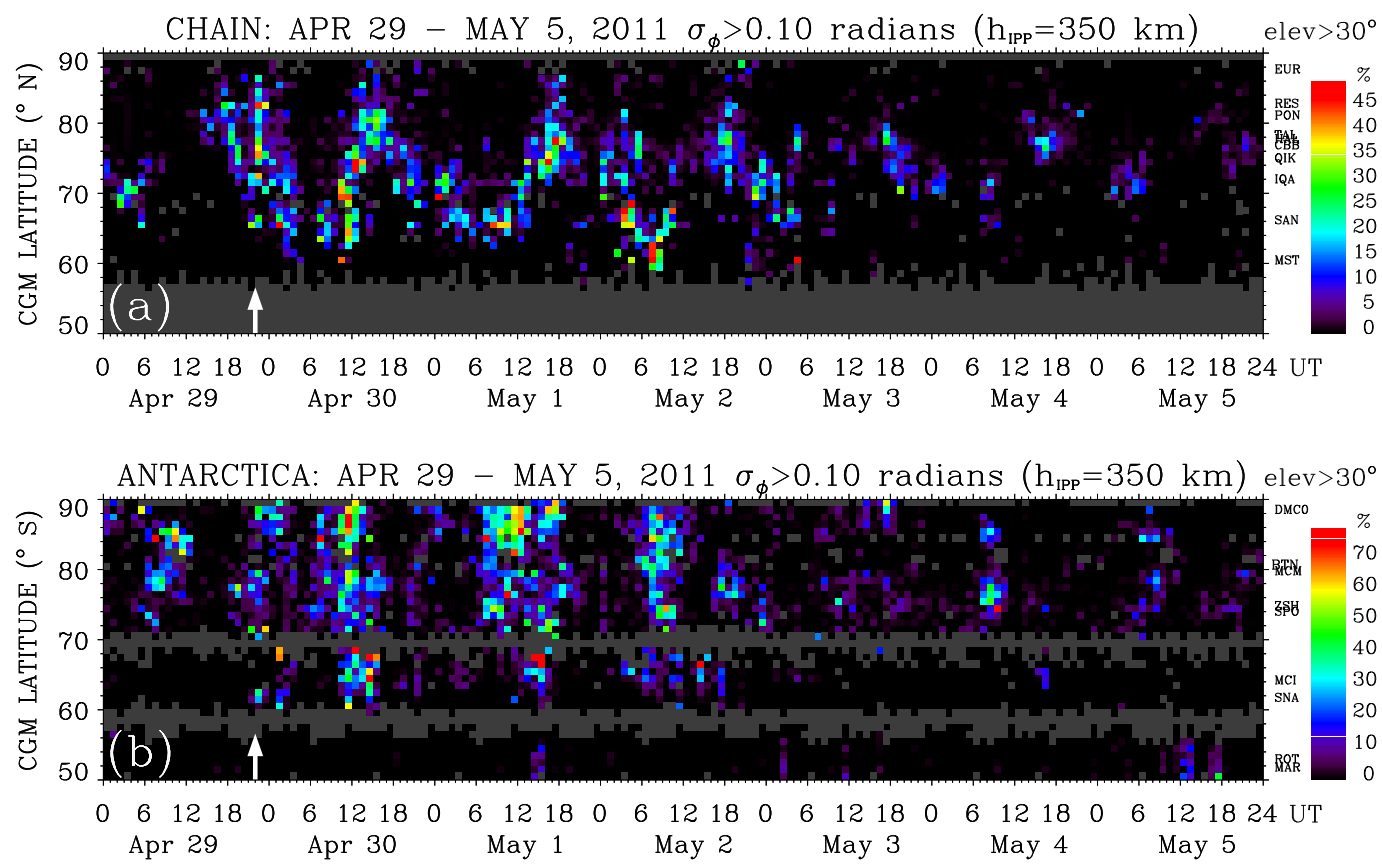

CHAIN+IGS: APR $29-\operatorname{MAY} 5$, 2011: DPR $>2 \mathrm{~mm} / \mathrm{s}\left(\mathrm{h}_{\mathrm{pPp}}=350 \mathrm{~km}\right)$ elev $>30^{\circ}$

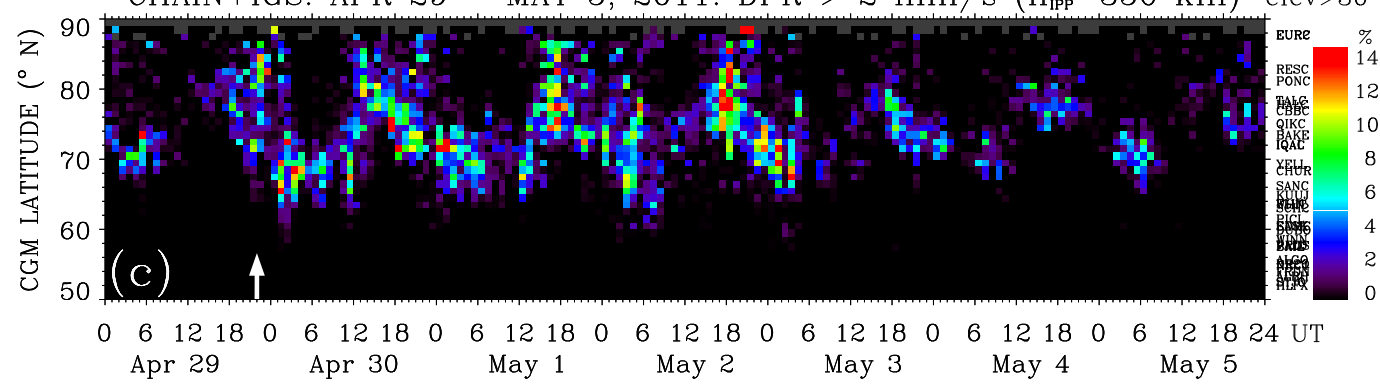

Figure 13. Phase scintillation occurrence from April 29 to May 5, 2011 as a function of CGM latitude and UT observed by (a) CHAIN and (b) GISTMs at southern high-latitudes. The occurrence of the proxy phase scintillation ( $D P R>2 \mathrm{~mm} / \mathrm{s}$ ) obtained from 1- $\mathrm{Hz}$ GPS data for (c) CHAIN and 40 more GPS receivers in the northern hemisphere. White arrows indicate the arrival time in UT of two ICMEs.

In the northern hemisphere, the brightened detached arc was captured by SUSSI (Figure 12a). About 50 min later, the SUSSI imager observed the arc stretching over many MLT hours from pre- to post-midnight in the southern hemisphere (Figure 12b). Simultaneous or slightly delayed scintillation events that co-located with the auroral forms were observed by approximately conjugate GPS receiver pairs. While the SP-IQA-QIK group of receivers observed the scintillation caused by the brightening arc in the dusk sector, nearly simultaneous scintillation was also detected in the post-midnight sector by approximately conjugate receivers in Svalbard (LYB0, NYA0 and YRGN) and in Zhongshan, Antarctica (Figure 12d).

Temporal and spatial co-location of scintillation was associated with the brightest emissions due to auroral break-ups and substorms, but moderate scintillation was frequently co-located with rayed arcs, corona displays and poleward-moving auroral forms. However, to further study scintillation associated with conjugate auroras in more detail, an all-sky imager and/or imaging riometer at IQA are required.

The IMF orientation is an important controlling factor in the solar-wind coupling to the magnetosphere and the location of the conjugate auroras. Østgaard et al. [2004] obtained an empirical model for the relation between longitudinal displacement of the conjugate point and IMF $B_{Y}$. These results are consistent with observations by Motoba et al. [2011], and they provide strong evidence that the hemispherical asymmetry is controlled by the IMF clock angle. The IMF $B_{Y}$ was strongly negative (dawnward) during the growth and expansion phase of a substorm event on April 29, which might explain a strong hemispherical asymmetry in the intensity of scintillation that was observed just after 21:40 UT (Figure 3). In the alfvénic solar wind that followed, the IMF $B_{Y}$ and $B_{Z}$ rapidly fluctuated around zero, but with smaller amplitudes. Thus it would be difficult to relate hemispherical differences, if any, observed in the scintillation occurrence. For the present study, simultaneous auroral images from both hemispheres were not available, and the GNSS coverage in 
the southern hemisphere was insufficient to examine such effects in detail. Inclusion of 1-Hz GPS receivers to obtain a proxy scintillation index (discussed below) and addition of more scintillation receivers with support by all-sky imagers at SP and IQA should make it possible to undertake a more detail analysis in the future.

\section{Interhemispheric comparison of the phase scintil- lation occurrence}

Figure 13a, b shows that the percentage occurrence of phase scintillation $\sigma_{\Phi}$ exceeding $0.1 \mathrm{rad}$ in the Canadian Arctic and in Antarctica, respectively, from April 29 to May 5, mapped as a function of latitude and universal time (UT) on a grid $1^{\circ} \times 1 \mathrm{~h}$, assuming the IPPs at 350 $\mathrm{km}$ altitude. The gray areas in Figure 13a, b indicate either complete absence or insufficient numbers of data points to estimate statistically significant scintillation occurrence in a given grid cell [Spogli et al. 2009]. The arrow in Figure 13a, b indicates the arrival time of the HSS / CIR. During the most active days of HSS (from April 29 to May 3), the scintillation occurrence was enhanced and the scintillation region expanded polewards and equatorwards in both hemispheres. The occurrence rate was generally higher at southern high latitudes (in Figure 13a, b, note the different scales), particularly in the polar cap. While the scintillation critically depends on the characteristics of the highpass filter, similar or identical scintillation monitors were used in this study.

The scintillation in the polar cap was due to the high occurrence of polar cap patches in the southern hemisphere. As the solar-wind velocity declined and the amplitude of the IMF fluctuations (Alfvén waves) diminished, the scintillation occurrence faded away. The marked differences in UT dependence of the occurrence are due to different longitude sectors represented in the database. Southern stations are at various longitudes, while CHAIN occupies a limited longitude interval corresponding to a narrower magnetic local time sector. As a result, there is a pronounced diurnal variation in CHAIN data (Figure 13a), with auroral scintillation dominating around magnetic midnight, and shifting to cusp and polar cap in the noon sector.

A proxy phase scintillation index, namely the $D P R$, was obtained as a difference between ionospheric delays encountered by GPS phase measurements over two consecutive epochs $1 \mathrm{~s}$ apart, averaged over $30 \mathrm{~s}$. Similar to $\sigma_{\Phi}$, the proxy index $D P R$ is projected to the vertical to account for geometrical effects on the measurements made at different elevation angles [Spogli et al. 2009]. For comparison with the phase scintillation index $\sigma_{\Phi}$, we use the absolute value of $D P R$ averaged over $60 \mathrm{~s}$. As shown for IQA in Figure 6, in terms of temporal occur- rence, $D P R$ compares reasonably well with $\sigma_{\Phi}$, but individual 60 -s values were only moderately correlated on April 29 (correlation coefficient, 0.51). Due to the under sampling at $1 \mathrm{~Hz}$, the DPR index does not capture the rapid changes of the phase that would cause strong scintillation; e.g., just after the onset of riometer absorption, the initial spike at 20:38 UT that is evident in $\sigma_{\Phi}$ was less pronounced in the DPR. Nevertheless, we find the DPR index to be a useful proxy to complement $\sigma_{\Phi}$ and to improve coverage in scintillation occurrence mapping.

Figure 13c shows the occurrence map of the DPR that exceeded $2 \mathrm{~mm} / \mathrm{s}$. Similar to the adopted $\sigma_{\Phi}$ threshold, the DPR threshold is somewhat arbitrary, but it was chosen to be safely above the DPR noise level. To determine thresholds that would give matching mean percentage occurrences for $\sigma_{\Phi}$ and $D P R$, further statistical analysis is required. About $40 \mathrm{GPS}$ stations with $1-\mathrm{Hz}$ sampling rate in North America are used to complement the CHAIN stations scintillation measurements [Ghoddousi-Fard and Lahaye 2012; Prikryl et al. 2013]. This map is very similar to the CHAIN phase scintillation occurrence map of $\sigma_{\Phi}>0.1 \mathrm{rad}$ (Figure 13a), although the percentages are higher for the latter threshold. Further evaluation of the DPR proxy index and comparison with $\sigma_{\Phi}$ will be carried out to justify its application as a phase scintillation proxy index [Prikryl et al. 2013]. Figure 14a-c shows the occurrence of $\sigma_{\Phi}>0.1$ $\mathrm{rad}$ and $D P R>2 \mathrm{~mm} / \mathrm{s}$ in the northern hemisphere and southern hemisphere as a function of magnetic latitude and MLT on a grid $2.5^{\circ} \times 1 \mathrm{~h}$ that spanned the interval from April 29 to May 5. The position of the statistical auroral oval for disturbed conditions [Feldstein and Starkov 1967, Holzworth and Meng 1975] is superposed. The occurrence of phase scintillation was higher in the southern hemisphere (Figure 14a) than the northern hemisphere (Figure 14b) polar cap and the cusp. SuperDARN radar in McMurdo observed copious backscatter from polar cap patches over Antarctica while the ionospheric backscatter observed in the Arctic by the PolarDARN component of SuperDARN was much weaker. This was very similar to another April event during a geomagnetic storm in 2010 [Prikryl et al. $2011 \mathrm{~b}]$, and it can be explained by seasonal variations in the occurrence of polar cap patches. The highest occurrence of polar patches, as identified in HF radar data from Halley, Antarctica, was observed from March to June [Rodger and Graham 1996]. In contrast, the lowest ionospheric backscatter occurrence in the northern polar cap was observed from April to August [Prikryl et al. 2010].

While in this study we have focused on scintillation associated with aurora over the South Pole and magnetically conjugate sites in Canada, the auroral oval is 

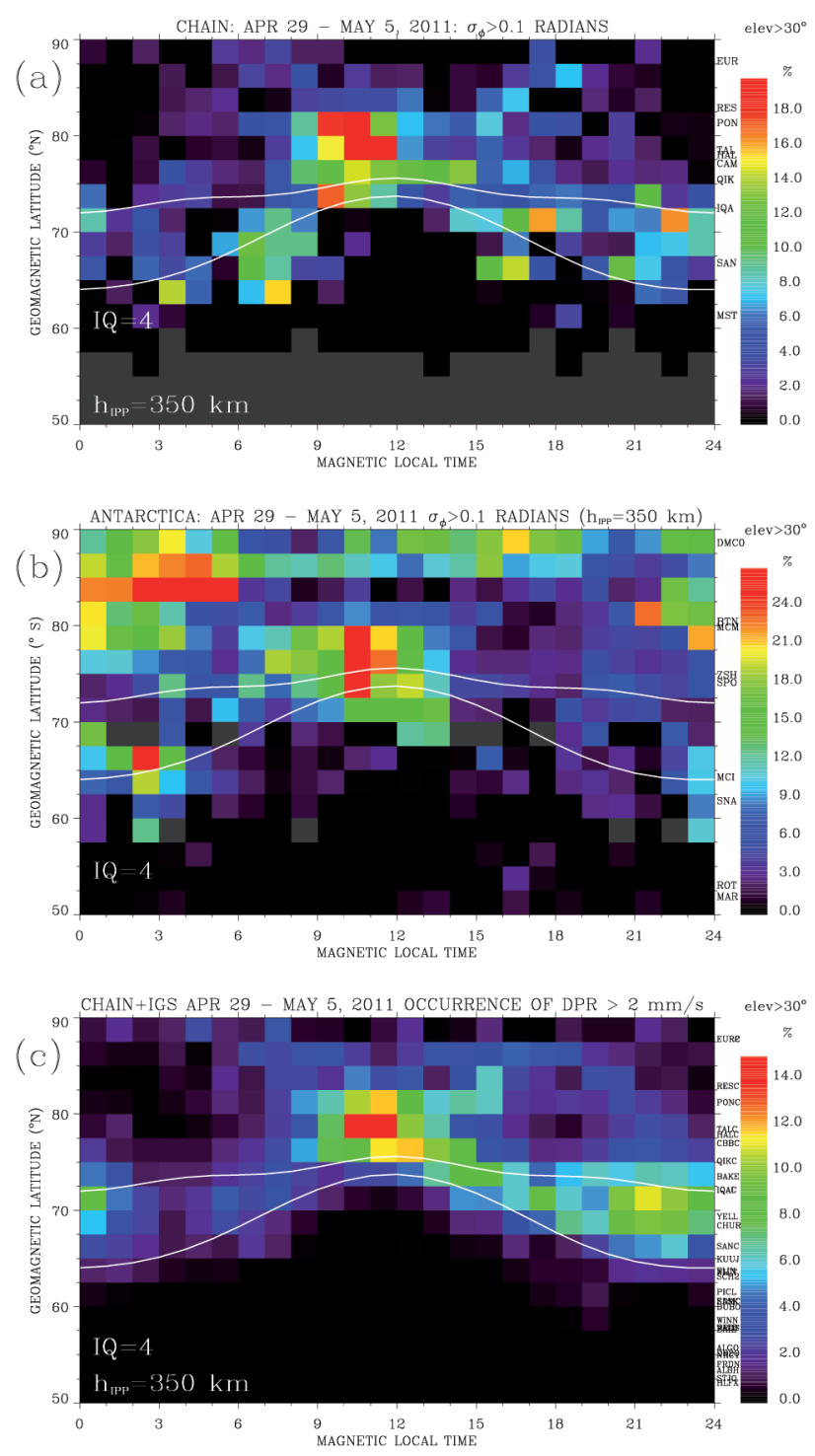

Figure 14. The occurrence of phase scintillation $\left(\sigma_{\Phi}>0.1\right)$ in the (a) northern and (b) southern hemispheres, and (c) the occurrence of the proxy phase scintillation index $(D P R>2 \mathrm{~mm} / \mathrm{s})$ as a function of MLT and CGM latitude. The statistical auroral oval for moderately disturbed conditions is superposed.

sparsely covered by scintillation GISTMs receivers. However, the use of $1-\mathrm{Hz}$ receivers to obtain the DPR index to characterize the scintillation occurrence can significantly improve the spatial coverage. Figure $14 \mathrm{c}$ shows a map of the percentage occurrence of $D P R>2 \mathrm{~mm} / \mathrm{s}$ that was obtained for 1-Hz Receiver Independent Exchange Format data for CHAIN augmented by many other $1-\mathrm{Hz}$ receivers. While the mapping for the adopted thresholds is very similar in the cusp and polar cap, which are covered mostly by CHAIN, the DPR occurrence gives a smoother average auroral oval that indicates auroral scintillation predominantly in the pre-midnight sector.

\section{Summary and conclusions}

Phase scintillation events at magnetically conjugate Antarctic and Arctic locations were observed during a period of a strong solar-wind HSS. The 558-nm auroral emission observed at SP was mapped on a geographic grid along with the GPS IPPs, including the conjugate locations of CHAIN stations, assuming a mapping shell height at $120 \mathrm{~km}$. At times of substorm onsets, the interhemispheric comparisons of phase scintillation that was co-located with the brightest auroral emission sometimes revealed simultaneity at approximately conjugate locations, and at other times revealed asynchrony with delays between the northern and southern auroral events. In one case, a large-scale arc that was detached from the auroral oval was observed by an all-sky imager at SP as well as space-borne DMSP SSUSI. Nearly simultaneous scintillation events at approximately conjugate locations in the northern and southern hemispheres were co-located with the arc. Phase scintillation was co-located with a variety of auroral forms. The strongest phase scintillation was associated with the brightest emissions due to auroral break-ups and substorms, but moderate scintillation was frequently co-located with rayed arcs and corona displays, including those observed in the cusp. The percentage occurrence of scintillation in the auroral oval was comparable between the hemispheres, but was significantly higher in the southern cusp and polar cap, which correlated with increased occurrence of patches over Antarctica. This agrees with the seasonal variation in polar-patch occurrence that is out of phase in the northern and southern hemispheres.

The proxy phase scintillation index $D P R$ is a very useful substitute for the phase scintillation $\sigma_{\Phi}$, to complement scintillation studies if $1-\mathrm{Hz}$ GNSS data are available. In the auroral oval, where the coverage by the 50-Hz GISTMs was sparse, the DPR occurrence maps show that phase scintillation predominantly occurs in the pre-midnight sector.

Acknowledgements. Infrastructure funding for CHAIN was provided by the Canada Foundation for Innovation and the New Brunswick Innovation Foundation. The CHAIN and Canadian Geospace Monitoring operation was conducted in collaboration with the Canadian Space Agency. The SP GPS, magnetometer, and riometer observations were supported in part by US National Science Foundation grants ANT-0840158 and ANT-0638587 to Siena College and New Jersey Institute of Technology, and South African National Antarctic Programme grant SNA2011120100008. These awards further support the University of Bath and Siena College GPS collaboration at the South Pole and McMurdo Stations, Antarctica. We further thank Drs. Louis Lanzerotti and Andrew Gerrard at the New Jersey Institute of Technology Center for Solar-Terrestrial Research for valuable discussions and input. This research was partly supported by the UK National Environment Research Council, grant AFI09/18, to the University of Bath, and the British Antarctic Survey. The British Antarctic Survey, the United States Antarctic Program, the South African National Antarctic Program and the University of Bath provided extensive logistical and engineering support. GPS ground data from the PoleNet and IGS campaigns were obtained through the University Navstar Consortium 
facility with support from the National Science Foundation and National Aeronautics and Space Administration, under a National Science Foundation Cooperative Agreement, EAR-0735156. Operation of the McMurdo SuperDARN radar is supported by grant ANT0944270 from the National Science Foundation Office of Polar Programs. The solar-wind data were obtained from Goddard Space Flight Center Space Physics Data Facility OMNIWeb (http: / / omni web.gsfc.nasa.gov/). The DMSP particle detectors were designed by Dave Hardy of Air Force Research Laboratory, and the data were obtained from Johns Hopkins University Applied Research Laboratory. The results presented in this study rely on data collected at magnetic observatories operated by the Canadian GeoSpace Monitoring Network, the Geological Survey of Canada. We thank the International GNSS Service and the national institutes that support them, and INTERMAGNET for promoting high standards of data archival practice.

\section{References}

Alfonsi, L., L. Spogli, G. De Franceschi, V. Romano, M. Aquino, A. Dodson and C.N. Mitchell (2011). Bipolar climatology of GPS ionospheric scintillation at solar minimum, Radio Sci., 46, RS0D05; doi:10.1029/ 2010RS004571.

Basu, S., E.J. Weber, T.W. Bullett, M.J. Keskinen, E. MacKenzie, P. Doherty, R. Sheehan, H. Kuenzler, P. Ning and J. Bongiolatti (1998). Characteristics of plasma structuring in the cusp/cleft region at Svalbard, Radio Sci., 33, 1885-1899; doi:10.1029/98RS01597.

Belcher, J.W., and L. Davis Jr. (1971). Large-amplitude Alfvén waves in the interplanetary 458 medium, 2, J. Geophys. Res., 76, 3534-3563.

Carlson, H.C. (2012). Sharpening our thinking about polar cap ionospheric patch morphology, research, and mitigation techniques, Radio Sci., 47, RS0L21; doi:10.1029/2011RS004946.

Donovan, E., T. Trondsen, L. Cogger and B. Jackel (2003). Auroral imaging within the Canadian CANOPUS and NORSTAR projects, Sodankylä Geophysical Observatory Publications, 92, 109-112.

Ebihara, Y., R. Kataoka, A.T. Weatherwax and M. Yamauchi (2010). Dayside proton aurora associated with magnetic impulse events: South Pole observations, J. Geophys. Res., 115, A04301; doi:10.1029/2009JA0 14760.

Feldstein, Y.I., and G.V. Starkov (1967). Dynamics of auroral belt and polar geomagnetic disturbances, Planet. Space Sci., 15, 209-230.

Ghoddousi-Fard, R., and F. Lahaye (2012). Monitoring GPS phase rate variations as a proxy scintillation index, Abstract G012-1465908, GNSS and the Atmosphere, AGU Fall Meeting, San Francisco, 3-7 December 2012.

Holzworth, R.H., and C.-I. Meng (1975). Mathematical representation of the auroral oval, Geophys. Res. Lett., 2, 377-380.

Huttunen, K.E.J., R. Schwenn, V. Bothmer and H.E.J.
Koskinen (2005). Properties and geoeffectiveness of magnetic clouds in the rising, maximum and early declining phases of solar cycle 23, Annales Geophysicae, 23, 625-641; doi:10.5194/ angeo-23-625-2005.

Jayachandran, P.T., et al. (2009). Canadian High Arctic Ionospheric Network (CHAIN), Radio Sci., 44, RS0A03; doi:10.1029/2008RS004046.

Kinrade, J., C.N. Mitchell, P. Yin, N. Smith, M.J. Jarvis, D.J. Maxfield, M.C. Rose, G.S. Bust and A.T. Weatherwax (2012). Ionospheric scintillation over Antarctica during the storm of 5-6 April 2010, J. Geophys. Res., 117, A05304; doi:10.1029/2011JA017073.

Laundal, K.M., and N. Østgaard (2009). Asymmetric auroral intensities in the Earth's northern and southern hemispheres, Nature 460, 491-493; doi:10.1038/ nature 08154.

Li, G., B. Ning, Z. Ren and L. Hu (2010). Statistics of GPS ionospheric scintillation and irregularities over polar regions at solar minimum, GPS Solutions, 14 (4), 331-341; doi:10.1007/s10291-009-0156-x.

Liu, W.W. (2005). Canadian space environment program and international living with a star, Adv. Space Res., 35, 51-60.

Mann, I.R., D.K. Milling, I.J. Rae, L.G. Ozeke, A. Kale, Z.C. Kale, K.R. Murphy, A. Parent, M. Usanova, D.M. Pahud, V. Lee, E.-A. Amalraj, D.D. Wallis, V. Angelopoulos, K.-H. Glassmeier, C.T. Russell, H.U., Auster and H.J. Singer (2008). The Upgraded CARISMA Magnetometer Array in the THEMIS Era, Space Sci. Rev., 141, 413-451; doi:10.1007/s1121 4-008-9457-6.

Motoba, T., K. Hosokawa, Y. Ogawa, N. Sato, A. Kadokura, S.C. Buchert and H. Rème (2011). In-situ evidence for interplanetary magnetic field induced tail twisting associated with relative displacement of conjugate auroral features, J. Geophys. Res., 116, A04209; doi:10.1029/2010JA016206.

Newell, P.T., T. Sotirelis and S. Wing (2009). Diffuse, monoenergetic, and broadband aurora: The global precipitation budget, J. Geophys. Res. 114, A09207; doi:10.1029/2009JA014326.

Nosé, M., et al. (2012). Wp index: A new substorm index derived from high-resolution geomagnetic field data at low latitude, Space Weather, 10, S08002; doi:10.1029/2012SW000785.

Osherovich, V.A., J. Fainberg and R.G. Stone (1999). Solar-wind quasi-invariant as a new index of solar activity, Geophys. Res. Lett., 26, 2597-2600.

Østgaard, N., S.B. Mende, H.U. Frey, T.J. Immel, L.A. Frank, J.B. Sigwarth and T.J. Stubbs (2004). Interplanetary magnetic field control of the location of substorm onset and auroral features in the conjugate hemispheres, J. Geophys. Res., 109, A07204; 
doi:10.1029/2003JA010370.

Paxton, L.J., D. Morrison, Y. Zhang, H. Kil, B. Wolven, B.S. Ogorzalek, D.C. Humm and C.-I. Meng (2002). Validation of remote sensing products produced by the Special Sensor Ultraviolet Scanning Imager (SSUSI) - a far-UV imaging spectrograph on DMSP F16, Proc. SPIE, 4485, 338.

Prikryl, P., J.W. MacDougall, I.F. Grant, D.P. Steele, G.J. Sofko and R.A. Greenwald (1999). Observations of polar patches generated by solar wind Alfven wave coupling to the dayside magnetosphere, Annales Geophysicae, 17, 463-489.

Prikryl, P., P.T. Jayachandran, S.C. Mushini, D. Pokhotelov, J.W. MacDougall, E., Donovan, E. Spanswick and J.-P. St.-Maurice (2010). GPS TEC, scintillation and cycle slips observed at high latitudes during solar minimum, Annales Geophysicae, 28, 1307-1316.

Prikryl, P., P.T. Jayachandran, S.C. Mushini and R. Chadwick (2011a). Climatology of GPS phase scintillation and HF radar backscatter for the high-latitude ionosphere under solar minimum conditions, Annales Geophysicae, 29, 377-392; doi:10.5194/an geo-29-377-2011.

Prikryl, P., et al. (2011b). Interhemispheric comparison of GPS phase scintillation at high latitudes during the magnetic-cloud-induced geomagnetic storm of 5-7 April 2010, Annales Geophysicae, 29, 2287-2304; doi:10.5194/ angeo-29-2287-2011.

Prikryl, P., R. Ghoddousi-Fard, B.S.R. Kunduri, E.G. Thomas, A.J. Coster, P.T. Jayachandran, E. Spanswick and D.W. Danskin (2013). GPS phase scintillation and proxy indices observed at high latitudes during a moderate geomagnetic storm, Annales Geophysicae, 31, 805-816; doi:10.5194/ angeo-31-805-2013.

Rodger, A.S., and A.C. Graham (1996). Diurnal and seasonal occurrence of polar patches, Annales Geophysicae, 14, 533-537.

Sato, N., T. Nagaoka, K. Hashimoto and T. Saemundsson (1998). Conjugacy of isolated auroral arcs and nonconjugate auroral breakups, J. Geophys. Res., 103, 11641-11652; doi:10.1029/98JA00461.

Sato, N., A. Kadokura, Y. Ebihara, H. Deguchi and T. Saemundsson (2005). Tracing geomagnetic conjugate points using exceptionally similar synchronous auroras, Geophys. Res. Lett., 32, L17109; doi:10.1029/ 2005 GL023710.

Smith, A.M., C.N. Mitchell, R.J. Watson, R.W. Meggs, P.M. Kintner, K. Kauristie and F. Honary (2008). GPS scintillation in the high arctic associated with an auroral arc, Space Weather, 6, S03D01; doi:10.1029/20 07SW000349.

Spanswick, E., E. Donovan, R. Friedel and A. Korth
(2007). Ground-based identification of dispersionless electron injections, Geophys. Res. Lett., 34, L03101; doi:10.1029/2006GL028329.

Spogli L., Lu. Alfonsi, G. De Franceschi, V. Romano, M.H.O. Aquino and A. Dodson (2009). Climatology of GPS ionospheric scintillations over high and midlatitude European regions, Annales Geophysicae, 27, 3429-3437.

Watson, C., P.T. Jayachandran, E. Spanswick, E.F. Donovan, and D.W. Danskin (2011). GPS TEC technique for observation of the evolution of substorm particle precipitation, J. Geophys. Res., 116, A00I90; doi:10.1029/2010JA015732.

Zhang, Y. and L.J. Paxton (2008). An empirical Kp-dependent global auroral model based on TIMED / GUVI FUV data, J. Atmosph. Solar-Terrest. Phys., 70, 1231-1242.

\footnotetext{
${ }^{\star}$ Corresponding author: Paul Prikryl,

Communications Research Centre, Ottawa, ON, Canada; email: paul.prikryl@crc.gc.ca.
}

C 2013 by the Istituto Nazionale di Geofisica e Vulcanologia. All rights reserved. 